\title{
Marcas de cantería en la iglesia Matriz de Moquegua, Perú
}

\section{Masons' Marks in the Matriz Church of Moquegua, Peru}

Artículo recibido el 29 de enero de 2019; devuelto para revisión el 5 de mayo de 2020; aceptado el 22 de junio de 2020; https://doi.org/IO.2220I/iie.I8703062e.202I.II8.2744

Raúl Carreño-Collatupa Grupo Ayar-Cusco, raulcarreno@ayar.org.pe, http://orcid.org/o0oo-0003-2073-2252.

Líneas de investigación Arte rupestre; epigrafía; geoarqueología; estudios culturales.

Lines of research Rock art; epigraphy; geoarchaeology; cultural studies.

Publicación más relevante "Disquisición sobre el juego de alquerque-leonera, sus tableros de piedra en el Cusco y su presencia en una imagen de Guamán Poma de Ayala", Boletín de Lima, núm. 174 (2014): 40-47.

Resumen La práctica de "firmar" los sillares mediante signos identificadores es muy antigua; fue muy común, sobre todo en la Europa medieval, de donde se trasplantó a América. El muro superviviente de la iglesia Matriz de Moquegua - muchas veces destruida por sismos y erupciones hasta su abandono total en I868 - contiene la mayor concentración conocida de signos de cantero del Perú. Se han reconocido IO7 tipos de signos alfabéticos, geométricos y figurativos grabados posiblemente entre 1784 y 1792 y que se caracterizan por su gran talla y la tosquedad de su trazo. Existen por lo menos dos tipos de ejemplares singulares de carácter figurativo que quizá no correspondan a marcas lapicidas, sino que podrían considerarse como litograbados. El artículo contiene, además, un repaso sobre el origen de las marcas de cantero y los estudios precursores sobre ellas.

Palabras clave Marcas de cantero; marcas de donante; Moquegua; gliptografía; litograbados; iglesia Matriz; picapedreros.

Abstract The "signing" of blocks of stone with identifying marks was a longstanding and very common practice, particularly in medieval Europe, whence it was transplanted to the Americas. The surviving wall of Moquegua's oldest church (the Matriz church)—many times destroyed by earthquakes and volcanic eruptions until its total abandonment in I868 - contains the largest known concentration of stonemason's 
marks in Peru. We have recognized 107 types of alphabetic, geometric and figurative signs, probably engraved between 1784 and 1792. Those marks are characterized by their large size and the coarseness of their stroke. There are at least two types of singular figurative engravings that may not correspond to lapidary marks, but could be considered as lithogravures. The article also contains an overview of the origin and the precursory studies of stonemason's marks.

Keywords Masons' marks; sponsors' marks; Moquegua; glyptography; lithogravures; Matriz church; stonecutters. 
DOI: https://10.22201/iie.18703062e.2021.118.2744

\author{
RAÚL CARREÑO-COLLATUPA \\ GRUPO AYAR-CUSCO
}

\title{
Marcas de cantería en la iglesia Matriz de Moquegua, Perú
}

\section{Introducción}

\section{$\mathrm{L}$} a iglesia Matriz de Moquegua — ciudad capital del departamento peruano del mismo nombre, ubicado al sur del país - ha estado signada por nicas, el sismo de 1868 marcó su abandono definitivo; se salvó incluso de desaparecer a principios de este siglo, cuando una autoridad edil quiso demoler el muro de contorno que da a la plaza de Armas y la calle Tacna (fig. I). Esta pared sobreviviente de tantas vicisitudes es, hasta donde se conoce, el lugar con mayor concentración (en cantidad, variedad y densidad) de signos lapicidas o marcas de cantería del Perú y, tal vez, de Latinoamérica.

Por otro lado, el tema de las marcas de cantería no ha sido prácticamente abordado en el Perú. Sin contar el artículo de Gutiérrez sobre las marcas de la iglesia de Santo Tomás, Chumbivilcas, y el libro y dos artículos de Ferdy Hermes Barbon, consagrados a las marcas en iglesias de Cusco y Arequipa, no se conocen más trabajos sobre este tema gliptográfico en el país.

\section{Vicisitudes de la iglesia Matriz de Moquegua}

El recinto original consagrado a san Pedro habría comenzado a construirse poco antes de 1590, "en adobe, cańa y barro [...] con cubierta de madera armada a par y nudillo (o con artesón), al modo mudéjar y sobreprotegido con 


\section{DOI: https://10.22201/iie.18703062e.2021.118.2744}

158

RAÚL CARREÑO-COLLATUPA

tejas". Otra referencia dice que "la levantó el Primer Teniente de Corregidor que tuvo Moquegua, Don Pedro Ladrón de Guevara y Sisa, con tres mil pesos en I595". ' Según Watanabe, a partir de la segunda mitad del siglo XVII, y predominantemente durante el siglo XviII, la labor de los albañiles en el templo consistió en el levantado de las portadas de piedra, la cornisa, el arco toral de ladrillo y cal con la típica bóveda volteada cubriendo la luz de naves y capillas. ${ }^{2}$ El mismo autor da una referencia de 1604 relativa a un segundo templo, "contiguo al edificio fundacional [...] flanqueado por la Casa del Vicario, la Calle del Medio y al frente de la Plaza Principal", como una respuesta a los graves daños que sufrió el primero por la erupción del volcán Huaynaputina en febrero de i6oo.

Esta erupción - considerada como la mayor de América Latina y una de las más fuertes de la historia mundial- emitió una enorme cantidad de material piroclástico que habría contribuido a hundir el techo, como ocurrió con muchas construcciones en Moquegua y Tacna. Según el cronista Vázquez de Espinosa, el volcán "arrojo de si tanto fuego, y ceniza que alcanço [la ceniza] mas de 200 leguas por todas partes y cayo en los nauios que nauegaban por la mar, al presente ay mucha [ceniza] a cabo de tanto tiempo por espacio de mas de I50 leguas". ${ }^{3}$ Felipe Guamán Poma de Ayala escribió al respecto: "Rebentó el bolcán y cubrió de zeniza y arena la ciudad y su jurisdicción, comarca; treynta días no se bido el sol ni luna, estrellas" ${ }^{4}$ El cronista Cobo describe cómo las bombas volcánicas hicieron hervir las aguas del río Tambo matando a los peces y que los "bramidos" del volcán se oyeron a más de 200 leguas.5 En Arequipa se cortó el suministro de agua y en toda la región sur hubo una alta mortandad de animales y pérdida de cultivos que indujeron una prolongada hambruna. ${ }^{6}$

I. Instituto Nacional de Estadística e Informática (INEI), Conociendo Moquegua (Moquegua: Oficina Departamental de Estadística e Informática, 2000), 39.

2. Luis Watanabe, "Aspecto histórico de la iglesia Matriz de Moquegua", consultado el to de septiembre de 20I8, en http://www.museocontisuyo.com/article.php?cd=II5.

3. Antonio Vázquez de Espinosa, Compendio y descripción de las Indias Occidentales, transcrito del manuscrito original por Charles Upson Clark (Washington: Smithsonian Institution, I948 [1630]), 469.

4. Felipe Guamán Poma de Ayala, Nueva Coronica y buen gobierno, Franklin Pease, ed. (Caracas: Biblioteca Ayacucho, 1980 [1615]), 389-402.

5. Bernabé Cobo, Historia del Nuevo Mundo, Marcos Jiménez de la Espada, ed., t. I (Sevilla: imprenta E. Rasco, I89o [1653]), 209 y 212.

6. María Eugenia Petit-Breuilh Sepúlveda, "Miedo y respuesta social en Arequipa: la 
DOI: https://10.22201/iie.18703062e.2021.118.2744

MARCAS DE CANTERÍA EN LA IGLESIA MATRIZ DE MOQUEGUA
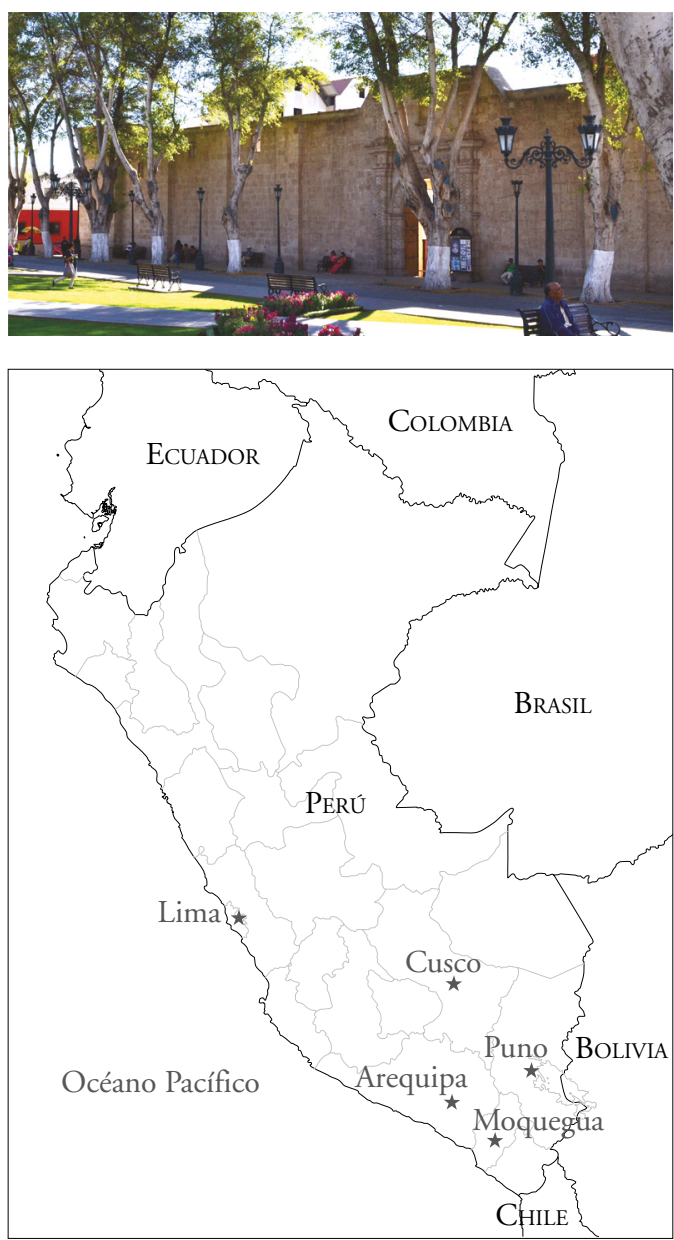

I. Ubicación y muros supervivientes de la iglesia Matriz de Moquegua que dan a la plaza de Armas (arriba) y la calle Tacna (abajo). Fotos del autor. Mapa dibujado por Citlali Coronel.

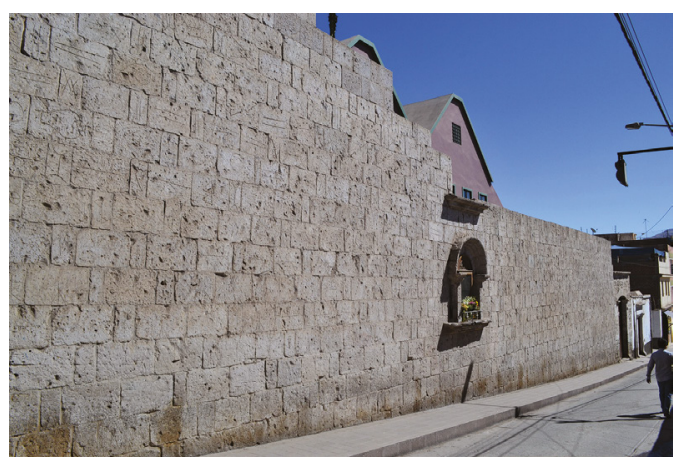




\section{DOI: https://10.22201/iie.18703062e.2021.118.2744}

160

RAÚL CARREÑO-COLLATUPA

Siguiendo la información recabada por Luis Enrique Kuon Cabello, ${ }^{7}$ sabemos que, tras el terremoto del 25 de noviembre de 1604, el capitán Alonso de Estrada, ecónomo eclesiástico, mandó construir en el mismo lugar las capillas de San Juan y San Antonio de Padua. El 27 de noviembre de I630 se produjo un segundo derrumbe, que se restauró gracias a los donativos de doña Mencía de Castro y del cura Ambrosio Javier Rodríguez. El I3 de noviembre de I655 ocurrió la tercera destrucción por causa sísmica, que generó otra reedificación en adobe y quincha a cargo del mayordomo Pedro del Alcázar. El sismo del 22 de agosto de I713, una vez más, dañó severamente el edificio.

La construcción primigenia — cuyo "eje de orientación y de ingreso fue invertido, pasando la puerta principal a la cabecera del 'altar mayor' y mudándose ésta a la simetría opuesta” en I678 - fue derruida completamente por el sismo del I3 de mayo de I784, que habría durado de cuatro a cinco minutos y que en Arequipa causó 54 muertos. ${ }^{8}$ Para tener una idea de la reciedumbre de este sismo hay que mencionar que los 22 edificios eclesiásticos existentes en esa época en Arequipa se dañaron, y diez de ellos se declararon como "irreparables". ${ }^{9}$ Ese mismo año, gracias al impulso y los donativos del párroco Lorenzo Vizcarra y Hurtado de Mendoza y de Juan Cabello Hurtado, se inicia la construcción del nuevo templo, esta vez de piedra y con estructura abovedada, consagrado a la advocación de Santa Catalina de Alejandría en septiembre de $1792,{ }^{10}$ año en que aparece grabado en un sillar de la cornisa de una de las torres. Allí se recibieron el 8 de octubre de 1798 los probables restos de santa Fortunata, que actualmente se hallan en el templo de San Francisco.

El nuevo edificio, a pesar del material empleado y de su diseño con arcos y contrafuertes, tampoco tuvo mejor suerte ante los terremotos: el del i 8 de

erupción de 1600 del volcán Huaynaputina (Perú)", Obradoiro de Historia Moderna, núm. 25 (2016): 67-94, http://dx.doi.org/I0.15304/ohm25.3154.

7. Luis Enrique Kuon Cabello, Retazos de la historia de Moquegua (s.l.: Talleres Gráficos de Abril, I98I), I9I-I94.

8. Yony Wuilfredo Amanqui Tacar, "Explicaciones sobre las causas de los terremotos dadas en la Arequipa colonial", Illapa. Revista Latinoamericana de Ciencias Sociales, núm.3 (2008): 253-270.

9. Juan Domingo Zamácola y Jáuregui, Relación puntual y verídica de los estragos que causó en la muy noble y leal ciudad de Arequipa, el espantoso terremoto acaecido el día 13 de mayo de 1784 , à que se agregan otras noticias (Arequipa: Imprenta de "La Bolsa", I889), 2I.

Io. Existe confusión sobre este punto: la fuente del INEI señala que la construcción del nuevo templo se inició en 1692 con un aporte de 20,000 pesos de dicho sacerdote. Watanabe, en cambio, indica que ese año fue el de su consagración. 
septiembre de I833, según Watanabe, "dañó la torre de la campana y cayó la del reloj, maltrató las dos naves colaterales, abrió la cúpula, colapsó parte de la portada y del presbiterio o sacristía, así como la pared del baptisterio". Finalmente, no se previó su reconstrucción tras el gran sismo del I3 de agosto de I868, según Kuon, debido a la severidad de los daños en toda la ciudad y a la necesidad de reconstruir cuatro iglesias, lo que insumió los recursos disponibles. Éste fue el mayor terremoto del siglo xix; el inglés William B. Stevenson y el profesor alemán Von Boeck "estimaron que la duración fluctuó entre siete y diez minutos"; ${ }^{I I} \tan$ inusitada duración explica su gran potencia destructora. Las noticias llegadas a Lima señalaban que "ya no existe el sur", que en Mollendo "el mar se salió como dos millas". José Toribio Polo ${ }^{\mathrm{r2}}$ reporta que este sismo causó I50 muertos en Moquegua, ciudad que "quedó en escombros", y que en Arica hubo dos maremotos, con olas que habrían alcanzado I2 y 17 metros de altura. Los efectos de este sismo derivaron en la profunda crisis financiera que afectó al país en la década siguiente, la que a su vez contribuyó a la derrota peruana en la guerra con Chile (1879-1883).

La iglesia tenía 56.43 metros de largo y 25.50 metros de ancho, constaba de tres naves con cubierta de bóveda de cañón o de medio punto, una típica cúpula en el crucero y una serie de capillas laterales. ${ }^{13} \mathrm{El} 28$ de diciembre de 1972 las ruinas se declararon Monumento Histórico; esto no impidió que el municipio lo usara como cochera hasta finales del siglo Xx. Los sismos de 1948 y del 23 de junio de 200I debilitaron aún más los restos. Hoy sólo quedan en pie el lienzo mural principal con el pórtico central de acceso que da a la plaza de Armas y el muro que asoma a la calle Tacna.

Cuando se construyó la actual catedral de Santo Domingo y se destinó el terreno para el edificio municipal de la provincia Mariscal Nieto se selló cualquier posibilidad de recuperar el edificio colonial. Como se indica, en 200I, tras otro sismo, el entonces alcalde Dante Zubia Cortez estuvo a punto a derribar lo que quedaba del muro supérstite. ${ }^{14}$ La intervención de las autoridades de cultura y de la población evitó tal desaguisado.

II. Manuel Fernández Canque, Arica I868. Un tsunami y un terremoto (Santiago: Universidad de Tarapacá, 2007), 88.

I2. José Toribio Polo, "Sinopsis de temblores y volcanes del Perú", Boletín de la Sociedad Geográfica de Lima, núm. 9, (1900): 15-95.

13. Kuon, Retazos de la historia de Moquegua, I93.

I4. Alberto Sánchez Aizcorbe, "Moquegua histórica", Revista Caretas (5 de julio de 200I). 


\section{DOI: https://10.22201/iie.18703062e.2021.118.2744}

I62

RAÚL CARREÑO-COLLATUPA

\section{Las marcas de cantería: breve repaso sobre su origen y estudio ${ }^{\mathrm{IS}}$}

Dice Louis van Belle: ${ }^{16}$ "Toute société, toute culture sont consubstantielles aux signes" ${ }^{17}$ Se afirma que los signos gliptográficos aparecieron incluso antes que la escritura; las marcas y señas presentes en el arte grutesco lo confirman.

Las iniciales referencias al término "marcas de canteros" (marques de tâcherons) —antes genéricamente denominadas signes lapidaires — se encuentran en artículos publicados por los franceses Didron, Malpièce y Viollet-le-Duc en los Annales Archéologiques de I845. A pesar de ello, el célebre Dictionnaire raisonné del tercero no consigna nada sobre este concepto y sólo en la última entrada del sexto volumen, "ouvrier", se alude de paso a las marcas como una prueba de que los obreros no recibían jornales, sino que eran pagados a destajo. ${ }^{18}$

En la segunda mitad del siglo XIx, Didron y Viollet-le-Duc establecieron la definición de las marcas de cantero como "signos lapidarios pertenecientes a la categoría de signaturas personales de los canteros, aparejadores y maestros de obra, que en muchos casos servían para señalar el trabajo realizado por cada uno, para así determinar el estipendio correspondiente". Un concepto más actual diría que son "signos tallados, grabados, trazados o dibujados que pueden ponerse en relación con una o más fases de la preparación, suministro y colocación de la piedra". ${ }^{19}$ Juan-Eduardo Cirlot $^{20}$ define las marcas como:

Signos distintivos, adoptados por una persona, cofradía, entidad, etc. Las marcas, desde la Antigüedad al presente, son de una variedad insondable y, junto a meras presentaciones de letras, nombres y anagramas, integran emblemas, símbolos,

15. Se considera necesario hacer un repaso sobre las marcas de cantería y los estudios precursores referidos al tema para una mejor comprensión de su funcionalidad.

I6. Louis van Belle, "Signes Gravés, signes écrits, signes reproduits", SIGNO. Revista de Historia de la Cultura Escrita, núm, 8 (200I): 2II-247.

17. "Toda sociedad, toda cultura es consustancial a los signos", algo que también puede leerse al revés: los signos son consustanciales a toda sociedad, a toda cultura.

I8. Eugène Viollet-le-Duc, Dictionnaire Raisonné de l'architecture française du XI au XVI siècle, t. 6 (París: V. A. Morel \& Cie. Éditeurs, I875), 454.

19. Yves Esquieu, Andreas Hartmann-Virnich, Anne Baud, Frédérique Costantini, Rollins Guild, Dominique Pitte, Daniel Prigent, Isabelle Parron, Nicolas Reveyron, Benjamin Saint-Jean-Vitus, Christian Sapin, Joëlle Tardieu, "Les Signes lapidaires dans la construction médiévale: études de cas et problèmes de méthode", Bulletin Monumental I65, núm. 4 (2007): 33I-358, https://doi.org/I0.3406/bulmo.2007.I489.

20. Juan-Eduardo Cirlot, Diccionario de simbolos (Barcelona: Editorial Labor, 1992), 247, 298 y 4 I2. 
alegorías, etc., y también ideogramas o formas intermedias entre éstos y el mero signo gráfico. Armeros, alfareros, canteros, albañiles, fabricantes de papel, etc., nos muestran en sus marcas un repertorio iconográfico variadísimo.

Y el signo lo define como:

la concreción, el síntoma de una realidad invisible e interior y, a la vez, el medio de recordar al pensamiento, esa realidad en un aspecto determinado. Determinación y sentido son inmanentes en el signo mientras que los ideogramas son representaciones gráficas —incididas, pintadas, dibujadas, etc. — de ideas o cosas mediante una reducción a los elementos esenciales que las pueden sugerir.

La tradición de estas marcas gliptográficas se remonta al antiguo Egipto, con 4,200 años de antigüedad; las de la pirámide de Keops son las más conocidas. Hay marcas en túmulos caldeos, en construcciones persas de Persépolis y Ekbatana (70o a. C.) y en la tumba del rey Ciro; en el circo de Nimes, en varios otros edificios romanos y en la gran cisterna bizantina de Estambul. ${ }^{21}$ Durante el periodo románico, las marcas servían para identificar a sus autores y con ello asegurar su paga. Pero fue en el apogeo del imperio romano de Oriente cuando se hicieron más conspicuas, hasta alcanzar su cumbre en Europa a partir del siglo XI, gracias al extraordinario auge constructivo del Medioevo que conllevó el crecimiento de las llamadas corporaciones de oficios, derivadas de los collegia fabrorum romanos, en especial dentro del rubro de la construcción.

En tanto marcas lapicidas con función identificadora, su práctica se inicia en el Medioevo:

Se cree que fue a partir del siglo xI cuando los signos lapidarios en Europa se sistematizaron y su empleo comenzó a regirse por logias que imponían normas para su trazado. La primera, y principal, que el cantero debía concebir su marca partiendo de un círculo, denominado primordial, a imitación del planteamiento que el maestro de obras aplicaba al edificio. La segunda, que alguna línea o parte de la marca contuviera al centro del círculo. Y, tercera, que la ejecución respetara los principios de la geometría clásica, la que obligaba a emplear como únicos instrumentos la regla y compás. ${ }^{22}$

2I. Vicente Lampérez y Romea, Historia de la arquitectura cristiana española en la Edad Media según el estudio de los elementos y monumentos (Madrid: Espasa Calpe, 1930), 55.

22. Álvaro Rendón, "Las corporaciones de canteros", consultado el I8 de septiembre 20I8, en 


\section{DOI: https://10.22201/iie.18703062e.2021.118.2744}

I64

RAÚL CARREÑO-COLLATUPA

La primera referencia conocida sobre la función de estos signos data de 1306, en un contrato suscrito por el deán de la catedral de Lincoln con un tal Richard of Stow, en el que se estipula que el pago, posiblemente diario, se haría por cada pieza marcada. ${ }^{23}$

Las marcas de cantería formaban parte de un sistema que reivindicaba el trabajo individual y colectivo, al "camuflar", cada sillar, nociones implícitas como la propiedad del trabajo del tallador y de la piedra (esto en el caso del dueño de la cantera o del comerciante intermediario), así como la responsabilidad sobre la calidad del trabajo y del material. ${ }^{24}$ Debió igualmente servir como una suerte de publicidad para el picapedrero o su taller colectivo, como lo expone Raúl Romero Medina, para quien "las marcas de los canteros reflejan una realidad individual, bien con carácter de remuneración, bien con carácter de publicidad y promoción". ${ }^{25}$ En muchos lugares de Europa, las llamadas "marcas de honor" se asignaban por el gremio correspondiente a los alarifes encargados de tallar piezas más complicadas que los simples sillares. Cualquier falsificación o alteración sin permiso se penaba, como lo confirma el reglamento de Basilea de $1513 .{ }^{26}$ Tampoco estaban permitidas las suplantaciones.

Estos signos recién comenzaron a estudiarse hacia la década de i840. Fue Adolphe Didron quien en I836 "llamó la atención de las Comisiones de monumentos y de los arqueólogos franceses sobre los signos grabados en muchas piedras de edificios medievales" ${ }^{27}$ En I84I, George Godwin dio a conocer un artículo que consigna 158 "masons' marks" recopiladas en diversos lugares de Europa; en I869 publica una comunicación con más registros de diez países europeos $;{ }^{28}$ algunas variantes de esos signos se dan en Moquegua. En I845 aparecen diversos artículos entre los cuales destacan los del famoso arquitecto

www.signoslapidarios.org/inicio/articulos/historia-de-la-arquitectura/I33-corporaciones-de-canteros.

23. Therese Martin, "Reading the Walls: Masons' Marks and the Archaeology of Architecture at San Isidoro, León”, en Therese Martin y Julie A. Harris, eds., Church, State, Vellum, and Stone: Essays on Medieval Spain in Honor of John Williams (Leiden: Brill, 2005), 373-4I2.

24. Van Belle, Signes Gravés, signes écrits, signes reproduits, 213.

25. Raúl Romero Medina, Diccionario bibliográfico de los signos lapidarios de España (Braine-le-Château: C.I.R.G., 20II): XIx.

26. Van Belle, Signes Gravés, signes écrits, signes reproduits, 220.

27. Lampérez, Historia de la arquitectura cristiana española en la Edad Media, 55.

28. George Godwin, "Something about Masons' Marks in Various Countries", en Papers Read at The Royal Institute of British Architects, Session 1868-69 (Londres: Royal Institute of British Architects, I869), I35-I44. 
Eugène Viollet-le-Duc, que incluían una tabla con marcas de diversos edificios franceses.

El primer documento "científico" conocido que se ocupa de estas marcas es la carta enviada en 1845 por el arquitecto Malpièce al director de Annales Archéologiques, que incluía una lámina con casi un centenar de signos. ${ }^{29}$ En el siguiente número de esa publicación, como parte de un artículo sobre signos lapidarios de la Edad Media, se presenta otra lámina con cerca de 300 marcas correspondientes a las catedrales de Estrasburgo (242) y Reims, recopiladas por Didron y Gustave Klotz. ${ }^{30}$ Pero es el abate Charles Auguste Auber, historiógrafo y canónigo de Poitiers, quien, a pesar del antecedente de Didron de 1836, reclama para sí el mérito de haber sido el primero en llamar la atención sobre estos signos (que detectó en la catedral de su ciudad en 1842), y para quien su gran variedad es sólo producto del azar, de una "arbitrariedad sin límites". Auber distingue entre la simplicidad de los signos franceses y la complejidad "pretensiosa" y de "líneas y contornos exagerados" de sus pares alemanes; afirma que el origen de estos signos no remonta más allá del siglo XI, que alcanza su auge en el siglo XIII y que su uso se prolongó hasta el siglo XVII; y hace un comentario crucial para evitar interpretaciones desviadas de carácter esotérico: "No debe de verse en esos signos ningún símbolo, incluso cuando se trate de copias exactas de estrellas, hojas, peces y de otros objetos en los cuales apenas se podría sospechar una alusión a nombres de personas sin importancia." ${ }_{31}$

En España, la primera referencia conocida al respecto fue dada por el erudito benedictino Pedro Xosé García Balboa (más conocido como fray Martín Sarmiento), quien en 1745 mencionaba unas "curiosas letras [...] señales de los pedreros para la coordinación de las piedras". ${ }^{32}$ José Antonio Martínez Prades ${ }^{33}$ señala que en i853 el opúsculo "Transcripción de las letras íberas de la muralla romana de Tarragona" de Buenaventura Hernández Sanahuja daba cuenta

29. Adolphe Napoléon Didron y Alexandre Jacques Malpièce, "Les Artistes du Moyen Âge et les signes lapidaires", Annales Archéologiques, núm. 2 (I845): 250-25I.

30. Adolphe Napoléon Didron y Gustave Klotz, "Signes Lapidaires au Moyen Âge”, Annales Archéologiques, t. 3 (I845): 5I-59.

31. Charles Auguste Auber, Chronologie des Signes lapidaires du Moyen Âge et sur leurs formes générales, Congrès Scientifique de Chartres (Chartres: Garnier Impremeur, 1869), 2-7.

32. Martín Sarmiento, Viaje a Galicia (I745), José Luis Pensado, ed. (Pontevedra: Ediciones Universidad de Salamanca I975), I2I-I22.

33. José Antonio Martínez Prades, "La gliptografía en la arquitectura medieval. Visión general y estudios en España", Revista Chilena de Estudios Medievales, núm. 3 (2013): 57-88. 


\section{DOI: https://10.22201/iie.18703062e.2021.118.2744}

de marcas en la muralla romana de Tarragona, interpretadas como un tipo de escritura ibérica. Gregorio Cruzada Villaamil ${ }^{34}$ y Eduardo de Mariátegui Martín ${ }^{35}$ publicaron los que tal vez sean los primeros artículos españoles sobre marcas de canteros como tales en construcciones medievales de Toledo. Pero es el arquitecto Vicente Lampérez quien en 1904 profundiza más en el tema, al dedicar a los signos lapidarios todo un capítulo de su Historia de la arquitectura cristiana española, en la que presenta un cuadro con marcas de varias iglesias españolas de entre los siglos XII y XVI, y desbarata de paso una serie de hipótesis acerca de su origen y significado, entre ellas la referida a que se trataría de un "alfabeto de un lenguaje mágico y exotérico, provenientes de la magia caldea y empleado como conjuro contra las potencias enemigas y suprasensibles de la Naturaleza"; plantea que "los signos lapidarios en los monumentos espańoles no sirven para clasificar las épocas de construcción, puesto que los hay iguales en edificios de edad muy diferente", y asegura que, en general, "son más complicados los signos conforme el monumento es más antiguo, y abundan los curvos en éstos y los rectos en los modernos". ${ }^{36}$

En I859, Edward Fitzgerald ${ }^{37}$ menciona para Irlanda, además de sus propios descubrimientos en las catedrales de Presburg y Ardmore, las marcas descubiertas en años anteriores por los reverendos James Graves y John W. Hopkins y el arquitecto W. Gillespie en la catedral de St. Canice de Kilkenny, en la abadía de Dunbrody y en las iglesias de Kinsale y Drumcliff. En la antigua Alemania eran comunes las "Hausmark" o marcas de familia.

Didron $^{38}$ aclara que las marcas son obra de los picapedreros y no de los albañiles. Eso implica, como lo estima para Estrasburgo, que en cada obra intervinieron al menos tantos alarifes como tipos de signos hay: unos 237 en Estrasburgo (siguiendo este criterio, habrían sido algo más de ioo en Moquegua), sin descartar que podría darse el caso de familias que usaron un mismo signo, lo cual explicaría, en parte, las variantes. También apunta que los

34. Gregorio Cruzada Villaamil, "Signos lapidarios del siglo xv en Toledo", El Arte en España. Revista Quincenal de las Artes del Dibujo, t. 2, (I863): 2II-2I9.

35. Eduardo de Mariátegui Martín, "Signos lapidarios de la torre del puente de San Martín (Toledo)", El Arte en España. Revista Quincenal de las Artes del Dibujo, t. 2 (I863): 55.

36. Lampérez, Historia de la arquitectura cristiana española en la Edad Media, 57-63.

37. Edward Fitzgerald, "On Ancient Mason-Marks of Youghal and Elsewhere; and the Secret Language of the Craftsmen of the Middle Ages in Ireland", The Journal of Kilkenny and South-East of Ireland Archaeological Society, New Series 2, núm. 2 (1859): 384-396.

38. Didron, Signes Lapidaires au Moyen Âge, 54-55. 
picapedreros recibían las indicaciones de dimensión de los albañiles, aunque sólo se exigía uniformidad en las medidas del ancho y la altura de los sillares mientras que la longitud era más aleatoria. En esos tiempos, las marcas no servían para otros fines, como fijar el posicionamiento de los bloques; así lo prueba un hecho constatado por Didron y Viollet-le-Duc: que las marcas están diseminadas sin orden ni concierto y muchas de ellas quedaban tapadas cuando la cara que las contenía se colocaba perpendicularmente a las caras expuestas del paramento. El marcado de piedras con la finalidad de señalar la identidad y el conteo fue una práctica muy expandida en Europa. Un diccionario de signos lapidarios, elaborado bajo la dirección de Louis van Belle (fundador del Centre Internationale de Recherches Glytographiques, que organiza un coloquio bianual sobre gliptografía), registra más de doce mil de estos signos sólo en Bélgica y el norte de Francia, muchos de la época moderna, lo cual demuestra la vigencia de esta práctica. Cabe anotar que también en el Perú aún se practica, aunque de manera restringida, el marcado, pero sólo en las piezas principales de un lote de mampuestos y baldosas, esto debido a que las actuales técnicas de intendencia, abastecimiento y almacenaje ya no requieren de mayores controles de los productos. Por lo general se trata de las iniciales de los canteros y del año de fábrica.

A pesar de su simplicidad, desde un punto de vista semiológico, estos signos responden a un proceso que, según Reveyron, citado por David Morel, ${ }^{39}$ se inscribe en una compleja red de relaciones provenientes de tres niveles de realidades: el motivo, el dibujo y la marca. El motivo es "un referente inmediatamente identificable a pesar de sus variaciones"; el dibujo es la "realización material del motivo que confiere a cada signo su carácter único", mientras que la marca "es una noción más compleja que asocia el motivo, el dibujo, una función y, eventualmente, una significación”.

Estos signos podrían ir más allá que una mera certificación de autoría. Morel ${ }^{40}$ cree que representan una valoración del individuo y un testimonio de su afirmación social: "La ligazón personal entre el obrero y su signo asocia al individuo con la obra que erige. El signo valora el trabajo del tallador de piedra y, más allá, su individualidad [...] El signo lapidario no es una finalidad. Es un vector de expresión” por el cual una obra eclesiástica resultaría ser "un espacio

39. David Morel, "Signes Lapidaires, techniques et qualifications en Auvergne au xirème siècle", Siècles. Cahiers du Centre d'histoire "Espaces et Culture», núm. 22, (2005): 53-66.

40. Morel, Signes Lapidaires, techniques et qualifications en Auvergne au XIIème siècle, 65. 


\section{DOI: https://10.22201/iie.18703062e.2021.118.2744}

I68

RAÚL CARREÑO-COLLATUPA

de libertad y de intercambios". Serían, en cierta medida, portadores de mensajes que, desde una perspectiva psicológica, reflejarían el trasfondo subjetivo y social en el cual se concibieron, pero eso ya sería materia de otro tipo de análisis semiótico que va más allá del alcance de este artículo.

$\mathrm{Al}$ parecer, las marcas no fueron sólo una práctica europea. En el castillo de Nagoya, residencia del clan Owari Tokugawa, líderes del último shogunato japonés (1603-1868), existen marcas de este tipo en el enrocado de la plataforma de base.

\section{Las marcas del cantero en Perú}

Muchos templos, edificios públicos y casas particulares del Perú contienen marcas de cantería. De los casos que venimos estudiando, es en Cusco donde son más abundantes. Pero es en la iglesia Matriz de Moquegua donde se da la mayor densidad y cantidad de marcas. Su profusión es impresionante: en la pared lateral que da a la calle Tacna (exceptuando las últimas hileras superiores de mampostería, que han reemplazado a los bloques originales) calculo grosso modo que alrededor de 90 por ciento de los sillares está marcado. Es igualmente llamativa su gran talla: tienen un promedio de 30 centímetros de largo, con algunos de más o menos 40 centímetros; muchas ocupan casi toda la cara expuesta de los sillares. La mayoría de marcas que he venido estudiando en Cusco y Puno rara vez superan los is centímetros. En general, tampoco en Europa son muy grandes.

No se conocen estudios latinoamericanos sobre estos signos epigráficos. Para el Perú hay cuatro trabajos: tres de Ferdy Hermes Barbon y uno de Tomás Gutiérrez. Barbon publicó en 2013 el libro Il códice ritrovato ${ }^{41}{ }^{4}$ con un minucioso inventario de marcas y signos de iglesias de Cusco y Arequipa, retomado en su artículo "Segni e marche ad Arequipa e Cusco città delle Ande Orientali" ${ }^{2}$ y, por último, el artículo "Le Marche lapidarie in Ayacucho e nella valle del Colca". Por su lado, el artículo "Marcas de canteros en Chumbivilcas (Perú) de Ramón Gutiérrez ${ }^{43}$ registra 95 tipos de marcas ubicadas sobre todo en las

4I. Ferdy Hermes Barbon, Il códice ritrovato (Crocetta del Montello: Antiga Edizioni, 2013).

42. Este artículo forma parte del libro Signum Lapidarium: Estudios sobre gliptografía en Europa, América y Oriente Próximo, editado por Raúl Romero Medina (Sevilla: Editorial Cultiva Libros, 2015).

43. Ramón Gutiérrez, Arquitectura virreynal en Cuzco y su región (Cusco: Editorial Universitaria UNSAAC, 1987), II9-I22. 

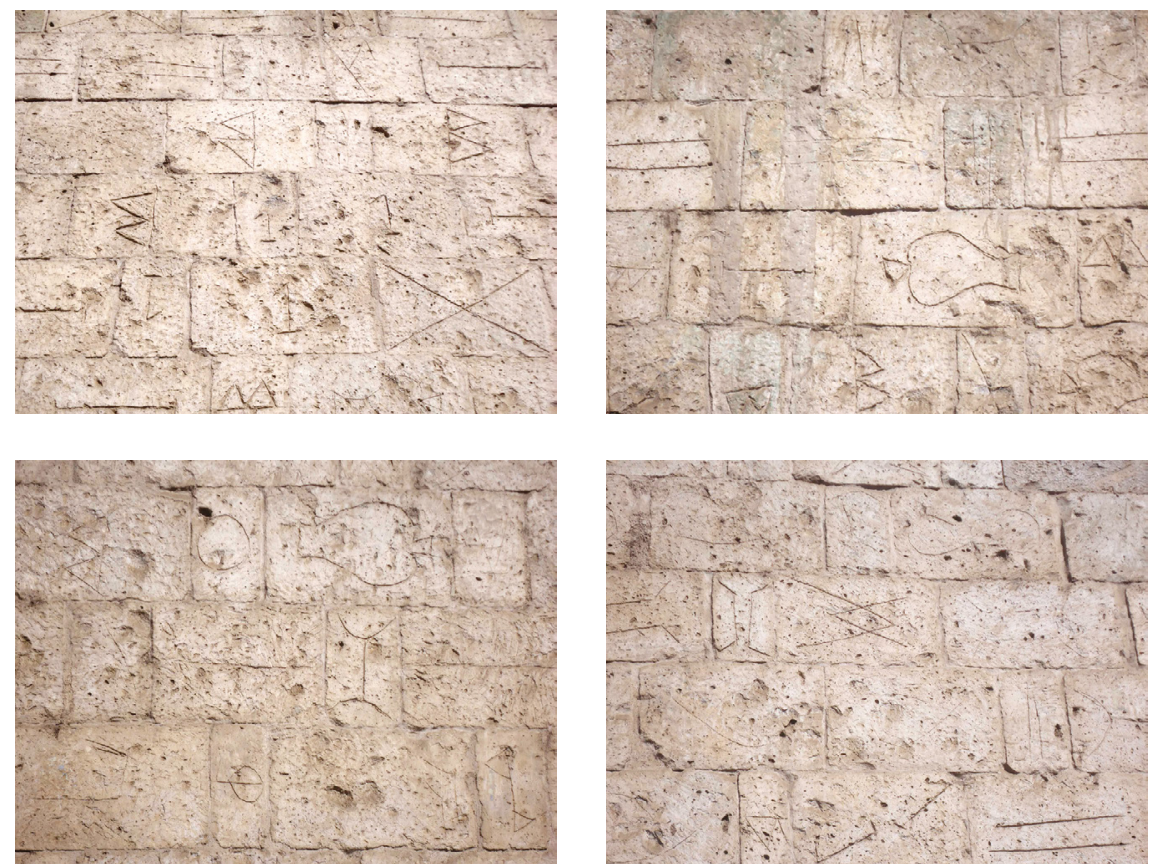

2. Ejemplos de marcas de cantero de la iglesia Matriz. Fotos del autor.

pilastras de la nave y en el sotocoro de la iglesia principal de Santo Tomás, capital de la provincia cusqueña de Chumbivilcas. ${ }^{44}$ Las marcas de Chumbivilcas y Moquegua tienen ciertos puntos en común: una gran variedad tipológica (más de 90 en ambos casos), su notable tamańo (aunque los de la Matriz son en promedio mayores) y el soporte lítico (toba volcánica, vulgarmente conocida como "sillar"). El gran tamaño de los signos parece responder a un condicionante

44. La búsqueda en internet arroja dos referencias para el artículo "Marcas de canteros en Chumbivilcas", que remiten a las Actas del III Coloquio sobre Gliptografía, realizado en Zaragoza, España, en 1982, cuyos autores son los hijos de Ramón Gutiérrez, Martín y Rodrigo Gutiérrez Viñuales; así también aparece en el catálogo de publicaciones de este último, consultado el 3I de octubre 20I9, en http://www.ugr.es/ rgutierr/publicaciones2.html. En el artículo se menciona que visitaron esta iglesia en 1976, cuando tenían 9 y II años, y habrían presentado la ponencia a los I5 y I7 ańos, respectivamente. Podría tratarse de un caso de doble precocidad intelectual, pero por prudencia preferimos consignar como referencia el libro del gran arquitecto argentino. 


\section{DOI: https://10.22201/iie.18703062e.2021.118.2744}

170

RAÚL CARREÑO-COLLATUPA

lítico, pues las marcas más grandes se dan casi siempre en este tipo de roca tobácea blanquecina, como lo corroboran las existentes en otras iglesias, como las de Pucará, Lampa, Espinar, Chumbivilcas, entre otros. Esto tal vez se deba a que lo grosero de la textura de estas tobas no permite un grabado más fino ni mantener un trazo regular, lo que induciría a realizar líneas largas para obtener figuras identificables que no se confundan o se distorsionen con las diaclasas u otras irregularidades de esta variedad de piedra.

En el Perú existe un curioso antecedente precolombino de marcas (que no tiene ninguna relación con las de edificios coloniales y republicanos), pero no en piedra sino en los adobes que constituyen varias huacas (santuarios) costeras, en especial de las culturas preincas Sicán y Mochica, y que muestran una variedad sorprendente: más de 220 tipos. Sólo en las huacas del Sol y de la Luna, Hastings y Moseley ${ }^{45}$ identificaron IOI tipos de makers' marks. Howard T. $\mathrm{Tsai}^{46}$ considera que eran una "marcación o símbolo de sus fabricantes [...] grabado en la superficie del adobe cuando estaba aún húmedo" y que servían para distinguir a cada sponsor individual o colectivo. Izumi Shimada, ${ }^{47}$ tomando el símil europeo, presume que son "representativas en su carácter [...] y pueden, muy bien, estar identificando el producto o la actividad principal del donante" y estima que más de 90 por ciento de los adobes usados en estructuras de Sicán Medio tienen estas marcas. M. Edward Moseley ${ }^{48}$ piensa que cada marca representaba a un grupo social específico, posiblemente a un grupo de trabajadores o a una comunidad (esto basado en que ciertas marcas se usaron por más de un siglo) y por la enorme cantidad de adobes fabricados (unos I43 millones sólo en la huaca del Sol). Estos grupos habrían producido, transportado e, incluso, colocado los adobes en segmentos particulares de la construcción. Hay pues una serie de convergencias casuales entre estas marcas precolombinas y las de raíz europea. Varios de los signos de la iglesia Matriz de Moquegua son semejantes a algunos de los adoberos de Sicán; se trata, obviamente, de una mera casualidad.

45. Mansfield Hastings y Edward Moseley, "The Adobes of Huaca del Sol and Huaca de la Luna”, American Antiquity 40, núm.2 (1975): 196-203.

46. Howard T. Tsai, "Adobe Bricks and Labor Organization on the North Coast of Peru", Andean Past, núm. Io (2012), I34-I69.

47. Izumi Shimada, Cultura Sicán. Dios, riqueza y poder en la costa norte del Perú (Lima: Edubanco, 1995), 32.

48. M. Edward Moseley, "Prehistoric Principles of Labor Organization in the Moche Valley, Peru”, American Antiquity 40, núm. 2 (1975): 19I-I96. 


\section{DOI: https://10.22201/iie.18703062e.2021.118.2744}

MARCAS DE CANTERÍA EN LA IGLESIA MATRIZ DE MOQUEGUA

\section{Tipología de las marcas de cantería moqueguanas}

Las marcas de canteros de la que fue la iglesia Matriz de Moquegua se conocen desde hace mucho tiempo; están incluso mencionadas en las guías turísticas. A pesar de ello, no se tienen estudios detallados sobre su origen ni tipología. Al partir de la premisa según la cual

los signos lapidarios son marcas personales de los canteros, expresivas de sus circunstancias particulares, y sólo en algunos casos hacen referencia a la obra; y que al propio tiempo tienen por objeto el conocimiento del trabajo efectuado por cada obrero, para facilitar la administración de la obra, ${ }^{49}$

quedaría por zanjar si las de Moquegua corresponden a marcas individuales o a aportes grupales.

Afirmar que son marcas de cantería parece evidente; sin embargo, la cuestión es más compleja por cuanto tal denominación no es específica y puede inducir a diferentes interpretaciones. La falta de información y de estudios gliptográficos en el Perú entorpece aún más cualquier indagación sobre su funcionalidad, la misma que puede ser muy variada, al abarcar desde las marcas de autoría o marcas personales (signum artificis), marcas artesanales, los signos o marcas de honor, hasta la heráldica gremial o corporativa, llamada también heráldica artesanal, ${ }^{\text {so }}$ sin descartar los signos utilitarios para orientar el acomodo de los sillares en un paramento, algo casi indispensable cuando se trata de bloques con tallados escultóricos u ornamentales.

Es casi seguro que los picapedreros fueron personas con muy poca educación o llanamente analfabetos. Recordemos que el oficio de cantero era uno de los más duros y despreciados en cualquier lugar; así, verbigracia, lo puso en evidencia el pintor realista francés Gustave Courbet cuando, según Jeffrey Ch. Peacock, ${ }^{\text {,I }}$ en una carta a su amigo el crítico Francis Wey explicaba su desaparecido cuadro llamado Los picapedreros, de quienes decía: "Es difícil imaginar una indigencia más completa y más manifiesta”, y eso, sin duda, se reprodujo en la América colonial. En tales condiciones no es plausible imaginar que

49. Lampérez, Historia de la arquitectura cristiana española en la Edad Media, 60.

50. Javier Alvarado Planas, Heráldica, simbolismo y usos tradicionales de las corporaciones de oficio: las marcas de canteros (Madrid: Ediciones Hidalguía-Hidalgos de España, 2009), IO-II.

5I. Jeffrey Ch. Peacock, A Chronology of Gustave Courbet's The Stone Breakers. A Supplement to the Exhibition, Critical Decor: What Works! (Coventry: Lanchester Gallery, 2014), 30. 


\section{DOI: https://10.22201/iie.18703062e.2021.118.2744}

172

RAÚL CARREÑO-COLLATUPA

el abecedario pudiese estar entre las referencias de los signos identificadores de esos humildes artesanos, ni resulta muy factible que haya en estas epigrafías alguna intención de simbolismo oculto, como al parecer habría en algunas marcas de iglesias góticas europeas, donde ciertos analistas creen encontrar simbología masónica, aunque resulta más o menos evidente que en realidad sólo se tratase de simples coincidencias. Los nombres o iniciales fueron poco usados como marcas de cantero en Europa; en Moquegua este hecho se repite, lo cual sería otro indicador de que los talladores eran iletrados.

En diferentes documentos y portales de promoción turística de Moquegua (Corpac, PerúTravel...) se reproduce, sin ninguna referencia bibliográfica, esta alusión a las marcas de la Matriz como "signos o símbolos que hablan de la forma y la política adoptadas por España para la construcción de los edificios públicos. Las marcas certifican la participación de las comunidades indígenas que, para probar su aporte, se vieron obligadas a diferenciar su producción y realizar este tipo de signos" y que "muchas de las piedras del muro están marcadas con símbolos que identificaron al patrón que donó la piedra cuando originalmente se construyeron [sic] la Iglesia". Esto podría plantear la posibilidad de que se trate de "marcas de donante" (sponsors' marks), un tipo de signos correspondientes a personas o grupos que encargaron la confección de los sillares como donativo y que pudieron exigir ser identificados mediante marcas específicas, esto teniendo en cuenta que en la época colonial muchas iglesias se construyeron gracias a donaciones, ya sea en dinero o en materiales o en imágenes y mobiliario. Para los sillares pudo darse esta modalidad; lo que nunca sabremos es si los donantes recurrieron a la práctica de solicitar un marcado especial, ya sea para contabilizar sus donativos o, simplemente, para dejar constancia de su dádiva. Al no haber antecedentes conocidos de este tipo de práctica en el Perú, aun dejando abierta la hipótesis de que se trate de marcas de donante, por ahora preferimos considerarlas genéricamente como marcas de cantero.

Al igual que en la iglesia chumbivilcana de Santo Tomás, la variedad de marcas moqueguanas es muy amplia; he identificado 7I tipos de signos que se podrían calificar como genéricos; contando variantes no sólo derivadas del trazo sino de aditamentos a manera de líneas suplementarias, este recuento muestra por lo menos IO7 tipos bien diferenciados. Hay signos que se encuentran en otros lugares (flechas, ganchos, aspas, tridentes, horquetas o furcas), incluso en Europa, donde se ha probado que esta repetición respondía, en ciertos casos, al desplazamiento de cuadrillas de artesanos contratados para diferentes obras. Es difícil imaginar algo así para Moquegua (una ciudad muy pequeña 
durante el virreinato), donde la cantidad, talla y diacronía de las construcciones eclesiásticas no era suficiente como para mantener una activa y suficiente demanda de talladores. La recurrencia de algunos signos que se encuentran en sillares de distintos lugares y épocas no es más que, reitero, fruto de la casualidad y no implica, en absoluto, la existencia de comunicaciones, continuidades $\mathrm{u}$ otro tipo de relaciones entre los alarifes, albañiles y picapedreros de distintas partes del mundo o de un mismo país o región.

Cabe anotar que los sillares con grabados escultóricos de tipo geométrico de la portada y el arco supérstites no presentan marcas visibles (que habrían alterado su carácter ornamental), lo que induce a suponer que fueron encargos especiales a talladores más especializados. De haberlas, se trataría de las ya mencionadas "marcas de honor" y estarían en las caras ocultas de los sillares.

En los muros de la Matriz de Moquegua se dan los tres tipos esenciales de signos epigráficos: alfabéticos, geométricos y figurativos. No se han identificado ideogramas, ni marcas monogramáticas ni emblemáticas, lo cual sería una prueba de que tanto el labrado/canteado como el marcado respondieron a una lógica organizacional diferente de las que eran practicadas en Europa, ratificando así su carácter identificador. Tampoco hay marcas de ajuste, de las destinadas a orientar la colocación de los sillares en los paramentos, es decir para guiar la fábrica o acomodo de la mampostería. Resulta sorprendente la ausencia de signos cruciformes, comunes en este menester.

\section{Signos alfabéticos}

Por la condición intelectual de los picapedreros resulta complicado encasillar a algunos signos moqueguanos en esta categoría. De manera condicional (fig. 3) colocamos en esta clase a la letra Z (2a) y al número i; de éste llama la atención una variante por pares trazados en diagonal y en posición especular (Ie). Grabados como 4, 5, 3 Oa y 46 (semejantes a las letra A, V, E y O) podrían ser asimilados a esta categoría pero sus muchas variantes hacen dudar sobre su carácter alfanumérico, por lo que se consideran geométricos, siguiendo la ya expresada convicción de que los picapedreros eran iletrados y que usaron estos signos por mera asociación con otras referencias visuales y mnemotécnicas; así, por ejemplo, los signos de tipo A podrían estar inspirados en los compases y escuadras, instrumentos de uso común en la albañilería y cantería de esos tiempos. 


\section{DOI: https://10.22201/iie.18703062e.2021.118.2744}

I74

RAÚL CARREÑO-COLLATUPA

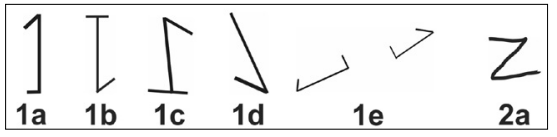

$2 a$
3. Signos de connotación alfabética. Dibujo del autor.

\section{Signos geométricos}

Constituyen la mayoría. Muchos son claramente asimilables a figuras determinadas (círculo, furca, flecha, aspa, paralelas...), pero otras son de carácter abstracto y de composición libre. Clasifico las marcas geométricas moqueguanas en dos grupos, aclarando que esto no responde a un criterio determinante sino a una apreciación que relaciona los signos del primer grupo con figuras geométricas reconocibles, simples o compuestas (fig. 4): triángulos (9, 27, 28), ángulos agudos $(5,6,8, \mathrm{IO})$, ángulos obtusos (I3, I4), círculos (30, 3I), aspas (I5, I6), flechas (26), horquillas o cruces furcas y tridentes $(23,25)$, paralelas $(20,2 \mathrm{I}$, 22). Los del segundo grupo (fig. 5) son de concepción más libre y van desde composiciones poligonales diversas hasta figuras en domo o curveadas. $\mathrm{Al}$ ser evidente que no se usaron moldes o plantillas, los tamaños son dispares y las variantes son múltiples, por lo que toda clasificación deviene relativa.

\section{Signos figurativos}

Hay hasta tres tipos de marcas que podrían incluirse en esta categoría (fig. 6): el cántaro (69), los zoomorfos (70) y las casas (7I). Los cántaros, con muchas variaciones, son los más abundantes de este grupo, mientras que los tres animales y las dos casas son ejemplares únicos. Por su cantidad y su esquema repetitivo, resulta evidente que la figura del cántaro es una marca de cantería, mientras que, como se verá en la siguiente sección, por su concepción e individualidad, las casas y los animales podrían caer en alguna otra categoría simbólica.

\section{¿Son todas marcas de canteros?}

La primera impresión es que todas son marcas de cantería; sin embargo, hay ciertos indicios que conducen a dudar de tal condición en al menos los tipos 70 y $7 \mathrm{I}$, las dos casas en forma de domo y las tres figuras que corresponden a camélidos o, eventualmente, a equinos. Con relación a las casas (fig. 7), a 


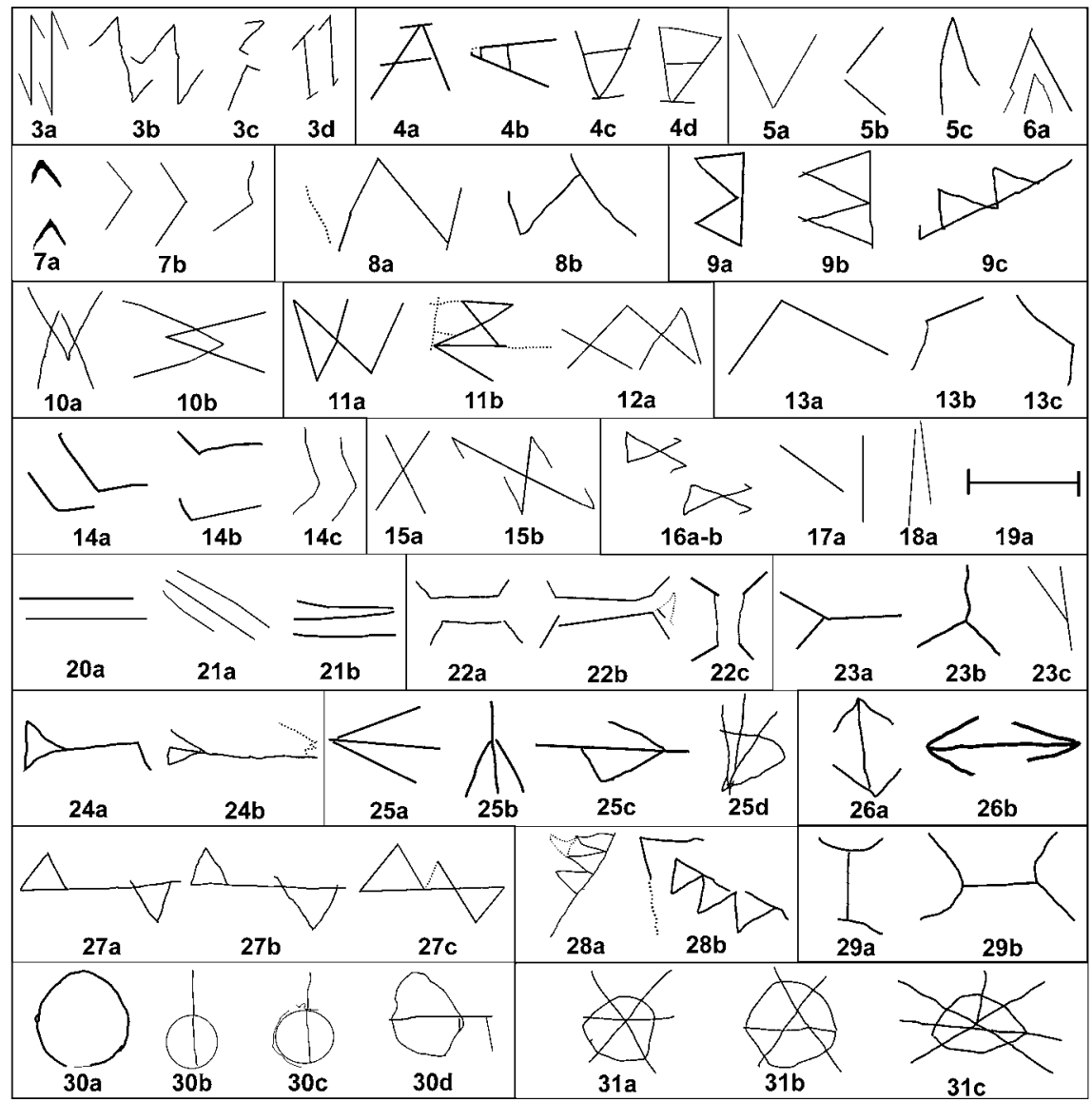

4. Marcas correspondientes a signos geométricos definidos. Dibujo del autor.

su individualidad, se suma la relativa complejidad de la composición gráfica, ambas con puertas de doble hoja, la 70 a con una planta al costado, mientras que la $70 b$ tiene un ornamento lateral de dos líneas paralelas en ángulo, detalles que las harían impropias para servir como marcas de cantería.

En cuanto a los mamíferos (fig. 8), el primero de ellos (7ra) está en postura de caminata. El segundo espécimen (7Ib), que muestra un animal en posición estática, plantea dudas por la línea vertical que se proyecta desde su lomo, lo que podría hacer pensar en un bosquejo de jinete. El tercero (7Ic), también 
DOI: https://10.22201/iie.18703062e.2021.118.2744

176 RAÚL CARREÑO-COLLATUPA

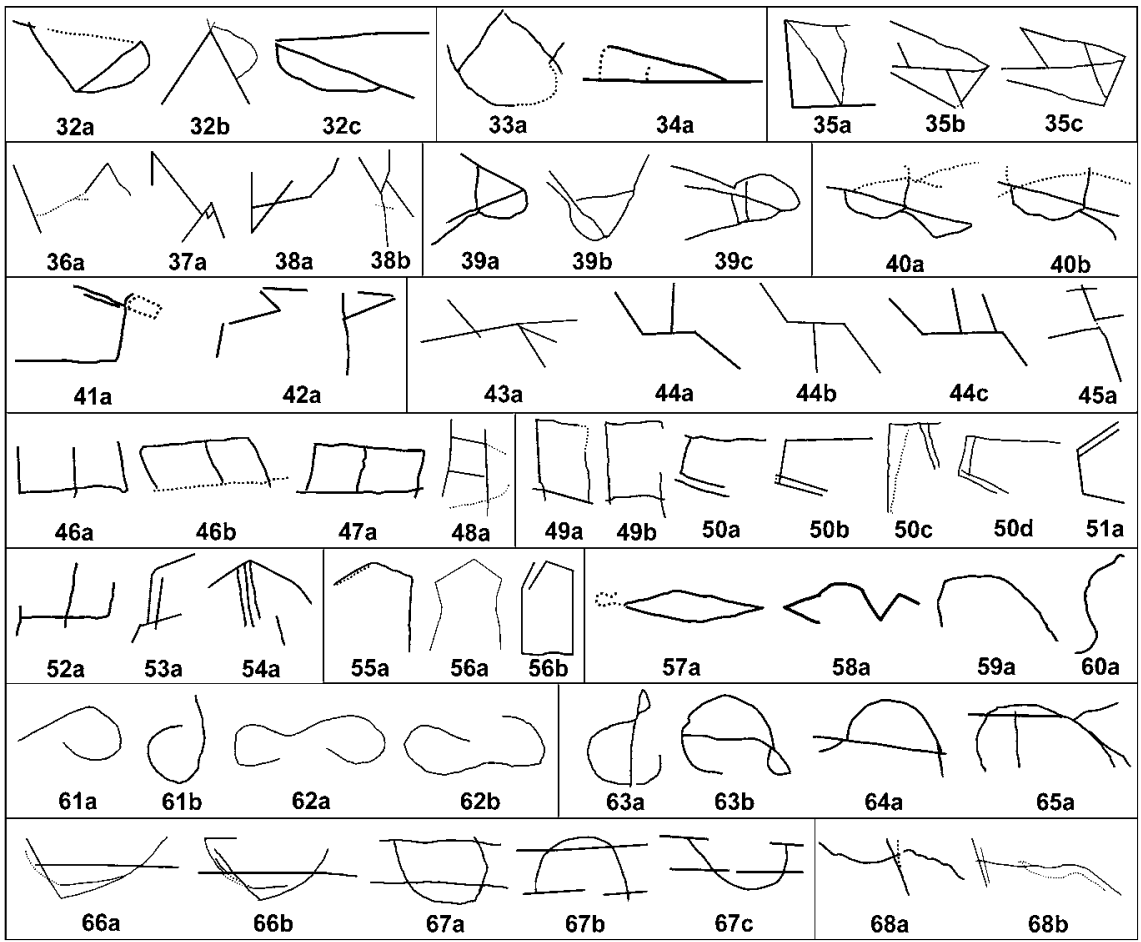

5. Marcas geométricas de composición libre o abstracta. Dibujo del autor.

andante, resulta más extraño por su larguísimo cuello y por una línea curva convexa que representaría un vientre (¿hembra preñada?), cuenta, además, con una línea punteada a manera de rienda colgante del cuello. Es difícil precisar si son camélidos o equinos. Aunque estos indicios no resultan definitorios, por sus largos cuellos y cortas caudas podrían ser camélidos; por el "jinete" y la rienda, caballos. Otra característica es que fueron delineados con reglas, tal como lo prueba la rectitud de las líneas, a diferencia de la gran mayoría de marcas hechas a mano alzada.

No podemos soslayar la alternativa de que estas marcas singulares sean producto de un mero afán lúdico o que sean litograbados o ideogramas rupestres con algún tipo de significación específica. $\mathrm{Al}$ no haber noticia de que tales marcas se hayan hecho durante la construcción del edificio ni tener documentos contractuales que den precisiones sobre encargos de labrado o 


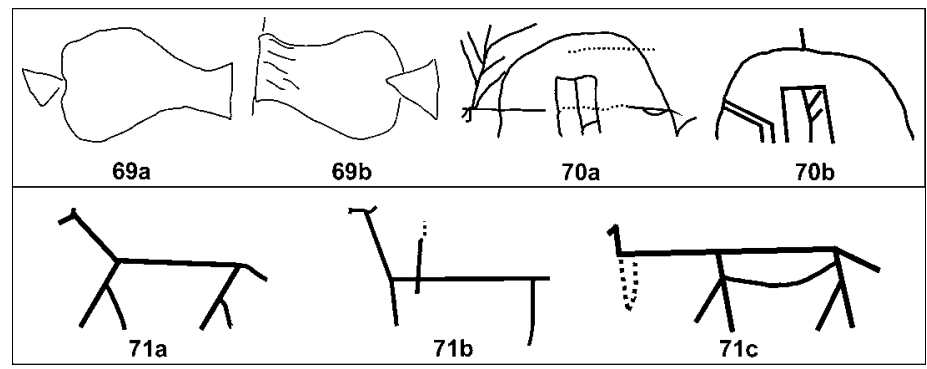

6. Marcas figurativas que representan cántaros, casas y animales. Dibujo del autor.

aprovisionamiento de sillares, es inviable emitir una conclusión taxativa al respecto.

A la inverosimilitud de estos signos de manifiesta naturaleza figurativa se suma el hecho de que se trata de ejemplares únicos: resultaría inaudito que algunos canteros hayan sido contratados para entregar un solo bloque labrado. Otro elemento que contribuiría a dudar del carácter de marca de cantería de estos cinco ejemplares es su ubicación: todos ellos se sitúan en hileras superiores del paramento, en puntos poco visibles, cerca de los ángulos que forman los contrafuertes. Existe la posibilidad de que estos emplazamientos no sean casuales y manifiesten la intención de "ocultar" o disimular símbolos de resistencia cultural (si en realidad lo fueron). Esta hipótesis se vería reforzada por la ubicación de litograbados precolombinos en cornisas, torres y otros puntos elevados y casi nunca transitados, como los que Germán Zecenarro Benavente ${ }^{52}$ reportó en la Catedral y la iglesia de La Merced del Cusco.

Sin embargo, este mismo hecho (su ubicación en la parte alta) podría también interpretarse desde otra perspectiva: que picapedreros que usaron estos signos hubiesen sido contratados cuando la construcción de los muros estaba ya muy avanzada, por lo que sus mampuestos sólo podían ubicarse en las hileras superiores de los paramentos, en las bóvedas y campanarios de la iglesia; al haber desaparecido éstas, al igual que las demás paredes y pilares, nunca podrá saberse si existieron más gliptografías de este tipo. De ser éste el caso, entonces las figuras antropomorfas y de casas no serían más que otras marcas

52. Germán Zecenarro Benavente, "Petroglifos y relieves en templos, conventos y casonas del Cusco", Arqueología y Sociedad, núm. I8 (2007): I79-2I0. 
DOI: https://10.22201/iie.18703062e.2021.118.2744

178

RAÚL CARREÑO-COLLATUPA
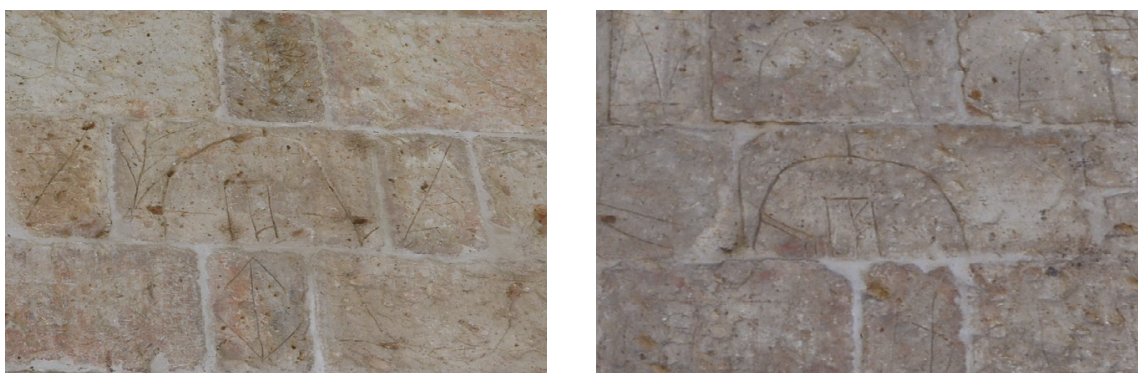

7. Grabados representando casas. Fotos del autor.

de cantería y no alguna otra expresión rupestre más elaborada. Como se ve, las dos hipótesis concernientes a las figuras de casas y animales (la de litograbados con cierto contenido semasiográfico o simbólico, y la de simples marcas de cantería) tendrían iguales opciones de validez, pero, al mismo tiempo estarían condenadas a quedar como tales, es decir propuestas sin probabilidad de comprobación, teniendo en cuenta que resulta imposible recuperar los sillares desaparecidos.

\section{Soporte litico}

Los mampuestos del muro de la iglesia Matriz son casi enteramente de la roca por lo común conocida como "sillar", y de un tipo que en el ámbito de la escultórica se denomina "piedra franca o mollar", es decir de "grano fino y de fácil labrado". Se trata de rocas piroclásticas ácidas, específicamente de tobas volcánicas de composición riolítica a dacítica. Aunque la pátina no permite una mayor precisión petrográfica, en las primeras hileras del paramento existen al parecer algunos sillares de tobas soldadas más duras (tal vez incluso ignimbritas) que, coincidentemente, no presentan gliptografías visibles.

A pesar de que en las laderas orientales de la ciudad hay afloramientos de toba blanca a crema del miembro inferior de la formación Moquegua del Terciario Superior, ${ }^{53}$ por el color de la mayoría de bloques del paramento (pardo

53. Eleodoro Bellido Bravo, Geología del cuadrángulo de Moquegua. Hoja: 35-u (Lima: Ingermmet, 1979), 42 y 45 . 
DOI: https://10.22201/iie.18703062e.2021.118.2744

MARCAS DE CANTERÍA EN LA IGLESIA MATRIZ DE MOQUEGUA
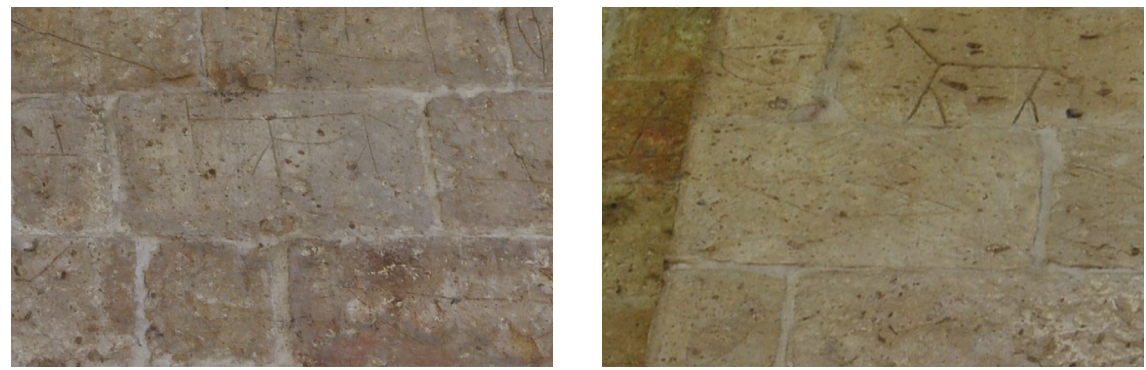

8. Dos de los tres posibles litograbados zoomorfos (probablemente camélidos andinos). Fotos del autor.

y crema rosáceo), las piedras parecen provenir de una unidad geológica posterior, la formación Huaylillas del Plioceno Medio-Superior, que afloran más al este de la ciudad. De origen las rocas eran más claras, pero, por un proceso de alteración o intemperismo, adquirieron su actual tinte pardo a ligeramente rojizo, aunque hay ejemplares que tienen ese tinte de forma natural.

Con excepción de las mencionadas tobas soldadas, estas rocas tobáceas son suaves y de fácil labrado, aunque, por su textura grosera y por la presencia de anfractuosidades en su estructura, no permiten alcanzar un acabado más fino por apomazado o pulimentado, por lo que, al igual que con el sillar arequipeño, el labrado no resulta delicado y la cara vista de los bloques presenta a menudo oquedades y otras irregularidades naturales, producto de la presencia de clastos incorporados de rocas preexistentes (xenolitos) o de huecos dejados por los gases volcánicos. Todo esto condicionó el trazo irregular de las marcas.

\section{Técnica de grabado y estado de conservación}

El trazado es simple, tosco, irregular, incluso en los ejemplares en los que se nota el empleo de reglas. Los surcos, delgados y someros, fueron incisos mediante rayado en la mayoría de los casos, al parecer de un solo trazo, usando punzones, estiletes o cinceles delgados, sin mayor trabajo de regrabado. En varios se advierte el uso de reglas mientras que la mayoría revela un trazado a pulso, es decir, a mano alzada. El ancho y la profundidad de los surcos no sobrepasan los 4 milímetros. 


\section{DOI: https://10.22201/iie.18703062e.2021.118.2744}

I80

RAÚL CARREÑO-COLLATUPA

La sequedad del clima moqueguano ha favorecido la conservación de los sillares y, en consecuencia, de las marcas epigráficas. En varios de los sillares, una pátina ligeramente ferruginosa ha protegido las superficies expuestas con una delgada costra dura que, a veces, se extiende hasta los surcos. Tampoco hay evidencias de vandalismo, aunque en las hileras inferiores, algo de pintura y otras manchas por contacto de manos y grasa afectan a una parte de los sillares. En términos generales, el estado de conservación de los sillares y sus marcas es muy bueno.

\section{Conclusión}

Puede afirmarse que la inmensa mayoría de signos lapicidas moqueguanos son marcas de canteros, es decir, de identidad. La cuestión irresuelta es si identificaban a artesanos individuales, a cofradías o a comunidades de picapedreros, por cuanto, como lo señala Van Belle,${ }^{54}$ la identidad puede ser de un individuo, de un equipo y hasta de una cantera. Ante la posibilidad de que se trate de organizaciones gremiales, al no saber si en Moquegua llegaron a constituirse gremios que eventualmente pudieron atribuir signos específicos a sus asociados, no será factible precisar si la tipología responde a un orden establecido o si fue fruto del mero azar. Tampoco hay suficiente sustento como para afirmar que, al menos en parte, se trate de "marcas de donante", como lo sugieren varias publicaciones de promoción turística.

Nada puede afirmarse sobre el potencial de sentido simbólico de al menos ciertas marcas; si lo hubo, es seguro que no fue algo premeditado ni conceptual, sino una expresión subconsciente de experiencias visuales acumuladas por los artesanos. Serían, en cierta medida, símbolos convencionales en el sentido que les da Cirlot:ss "signos que tienen relación con algo, pero relación establecida con mayor o menor arbitrariedad y, en la mayoría de casos, sin esa conexión de profundidad, analógica, que constituye el auténtico símbolo".

Es casi seguro que las marcas correspondan a las últimas décadas del siglo XviII y que hayan sido grabadas durante la reconstrucción que siguió al terremoto de mayo de 1784 , es decir entre ese año y 1792, cuando se consagró el

54. Van Belle, Signes Gravés, signes écrits, signes reproduits, 213.

55. Cirlot, Diccionario de simbolos, 412-413. 
templo. Esta hipótesis se basa en que los anteriores edificios eran esencialmente de barro y quincha.

Por último, se debe de descartar, por absurda, cualquier interpretación que apunte a hacer creer que estas marcas son signos esotéricos, religiosos, arcanos masónicos o mensajes de sectas, como ya lo pretende la corriente del turismo llamado "esotérico". \$ 